\title{
Allergen Sensitization Is Associated with Increased DNA Methylation in Older Men
}

\author{
Joanne E. Sordillo ${ }^{a, c}$ Nancy E. Lange ${ }^{a-c}$ Letizia Tarantini ${ }^{f} \quad$ Valentina Bollati $^{f}$ \\ Antonella Zanobetti ${ }^{\mathrm{e}}$ David Sparrow ${ }^{d}$ Pantel Vokonas $^{\mathrm{d}}$ Joel Schwartz ${ }^{\mathrm{e}}$ \\ Andrea Baccarelli ${ }^{e} f$ Dawn DeMeo ${ }^{a-c}$ Augusto A. Litonjua ${ }^{a-c}$ \\ ${ }^{a}$ Channing Laboratory, ${ }^{b}$ Division of Pulmonary and Critical Care Medicine, Department of Medicine, Brigham \\ and Women's Hospital, ' Harvard Medical School, 'Veterans Affairs Boston Healthcare System and Department of \\ Medicine, Boston University School of Medicine, and e Department of Environmental Health, Harvard School of \\ Public Health, Boston, Mass., USA; ${ }^{f}$ Center of Molecular and Genetic Epidemiology, Department of Environmental \\ and Occupational Health, Università degli Studi di Milano and IRCCS Maggiore Policlinico Hospital, Mangiagalli and \\ Regina Elena Foundation, Milan, Italy
}

\section{Key Words}

Allergen sensitization · DNA methylation · Alu $\cdot$ Long interspersed nuclear element-1

\begin{abstract}
Background: Variation in epigenetic modifications, arising from either environmental exposures or internal physiological changes, can influence gene expression and may ultimately contribute to complex diseases such as asthma and allergies. We examined the association of asthma and allergic phenotypes with DNA methylation levels of retrotransposon-derived elements. Methods: We used data from 704 men (mean age 73 years) in the longitudinal Normative Aging Study to assess the relationship between asthma, allergic phenotypes and DNA methylation levels of the retrotransposon-derived elements Alu and long interspersed nuclear element (LINE)-1. Retrotransposons represent a large fraction of the genome (>30\%) and are heavily methylated to prevent expression. Percent methylation of Alu and LINE-1 elements in peripheral white blood cells was quantified using PCR pyrosequencing. Data on sensitization to common allergens from skin prick testing, asthma and methacholine responsiveness were gathered approximately 8 years prior
\end{abstract}

to DNA methylation analysis. Results: Prior allergen sensitization was associated with increased methylation of Alu ( $\beta=0.32$ for sensitized vs. nonsensitized patients; $p=0.003$ ) in models adjusted for pack-years of smoking, body mass index, current smoking, air pollutants, percentage of eosinophils, white blood cell count and age. Of the men interviewed, $5 \%$ of subjects reported a diagnosis of asthma. Neither Alu nor LINE-1 methylation was associated with asthma. Conclusions: These data suggest that increased DNA methylation of repetitive elements may be associated with allergen sensitization but does not appear to be associated with asthma. Future work is needed to identify potential underlying mechanisms for these relationships.

Copyright $\odot 2012$ S. Karger AG, Basel

\section{Introduction}

Allergic diseases are known to arise from both genetic and environmental causes. Epigenetics, or the study of changes to the genome peripheral to the DNA sequence itself (i.e. histone modifications, RNA interference and DNA methylation), is key to understanding how the environment alters the function of genes. DNA methyla-

\section{KARGER}

Fax +4161306 1234 E-Mail karger@karger.ch www.karger.com
(C) 2012 S. Karger AG, Basel

$1018-2438 / 13 / 1611-0037 \$ 38.00 / 0$

Accessible online at:

www.karger.com/iaa
Correspondence to: Dr. Joanne E. Sordillo

Division of Pulmonary and Critical Care Medicine, Department of Medicine

Brigham and Women's Hospital

181 Longwood Ave, Boston, MA 02115 (USA)

E-Mail rejoa@channing.harvard.edu 
tion, which occurs through the addition of methyl groups to cytosines located within CpG dinucleotides, is a reversible modification that can alter chromosome stability and suppress gene transcription. Epigenetic pathways, mediated by environmental exposures, may change gene expression profiles, ultimately resulting in a particular phenotype [1]. A number of environmental exposures, including air pollution and dietary factors, have been shown to influence the epigenome [2].

Epigenetic changes are important in immune system development and may also have relevance for asthma and allergic disease etiology. The differentiation of $\mathrm{T}$ cells, a process necessary for normal immune function, is guided by changes in DNA/histone methylation and/or histone acetylation [3]. During differentiation of naïve T cells into type $1 \mathrm{~T}$ helper (Th1) cells, the promoter region in the interferon (IFN)- $\gamma$ gene is progressively demethylated (thereby increasing the expression of this Th1 cytokine that enhances the Th1 response) [4-5, 7-8]. Epigenetic mechanisms are also known to influence type $2 \mathrm{~T}$ helper (Th2) differentiation and may impact the expression of forkhead box P3 and T regulatory cell function [9-11]. While the opportunity for epigenetic-driven changes in gene expression provides plasticity in immune function, it also makes the system susceptible to aberrant modifications that could ultimately give rise to an allergic disease phenotype. In fact, studies on epigenetic regulation of $\mathrm{T}$ cells have led to the hypothesis that environmental exposures influencing DNA methylation may increase allergic disease risk by suppressing pathways (Th1 and T regulatory cell differentiation) that inhibit differentiation of allergy-promoting Th2 cells $[12,13]$. Consistent with this hypothesis, some [6,14] but not all [15] human and animal studies show an association between dietary supplementation with folate (a methyl donor) during pregnancy and increased risk of asthma in offspring.

While DNA methylation has been investigated in relation to a variety of diseases, little is known about its relationship to asthma and allergic disease. A large portion of DNA methylation sites are located within retrotransposons, repetitive sequences which are generally not expressed. Demethylation of these sequences could potentially interfere with proper expression of other genes [16]. Long interspersed nuclear elements (LINEs) and short interspersed nuclear elements are retrotransposon-derived repetitive elements present in mammalian genomes. Retrotransposons utilize an RNA intermediary to create cDNA copies of themselves for reinsertion into the genome [17]. LINE-1 elements, which are 6,000 base pairs in their full form, comprise at least $17 \%$ of the human ge- nome. More than one million copies of Alu sequences, a type of short interspersed nuclear element, are also interspersed throughout the genome [17]. In addition to serving as markers of DNA methylation in a large portion (approx. 30\%) of the genome, LINE-1 and Alu repetitive elements may also directly influence asthma and allergic disease pathogenesis. Unmethylated $\mathrm{CpG}$ sequences in Alu repeats may mimic bacterial DNA CpG motifs [18], with the potential to stimulate the innate immune system and possibly mediate an allergic disease response. Transcriptionally active LINE-1 elements are potential activators of IFN- $\gamma$ and other proinflammatory mediators through toll-like receptor pathways [19], with possible implications for allergies and asthma.

In this study, we determined whether methylation of Alu and LINE-1 (two common categories of retrotransposon-derived elements) was associated with allergen sensitization, airway hyperresponsiveness or asthma. To our knowledge, this is the first epidemiological study to examine DNA methylation of Alu and LINE-1 and allergic disease.

\section{Materials and Methods}

\section{Normative Aging Study}

This study included 704 elderly men who, as of March 1999, were active participants in the Normative Aging Study. The Normative Aging Study cohort was established by the Veterans' Administration in 1961, which enrolled men 21-80 years of age from the greater Boston area (Mass., USA) who were free of known chronic medical conditions [20]. Since the time of enrollment, participants have had comprehensive clinical examinations at 3to 5-year intervals. In examinations that took place between March 1999 and November 2007, participants agreed to donate at least one blood sample for DNA. A physician elicited a complete medical history and smoking history using the American Thoracic Society questionnaire [21]. The questionnaire (ATS-DLD-78) [21] was administered to each participant to obtain information on smoking habits, respiratory symptoms and illness, an average of 8 years prior to blood collection for DNA methylation (range 5-17.5 years). Of the 704 men with blood samples for DNA methylation data, 669 had questionnaire data for asthma. Men who reported a doctor's diagnosis of asthma were classified as asthmatic. All participants gave written informed consent. This study was reviewed and approved by the institutional review boards of all participating institutions.

DNA Methylation of Repetitive Elements

DNA was extracted from stored frozen buffy coat of $7 \mathrm{ml}$ of whole blood, using QiAmp DNA blood kits (Qiagen). DNA methylation was quantitated using bisulfite PCR and pyrosequencing, as described previously $[22,23]$. PCR primers were designed towards consensus LINE-1 and Alu sequences and allowed for the amplification of a representative pool of repetitive elements to 
Table 1. Characteristics of the Normative Aging Study population at the time of DNA methylation analysis

\begin{tabular}{|c|c|}
\hline Age, years $^{1}(n=704)$ & $72.7(6.7)$ \\
\hline Body mass index ${ }^{1}(\mathrm{n}=702)$ & $28.5(4.1)$ \\
\hline \multicolumn{2}{|l|}{ Smoking, $\mathrm{n}$} \\
\hline Never & $210(30 \%)$ \\
\hline Quit & $463(66 \%)$ \\
\hline Occasional & $2(0.3 \%)$ \\
\hline Regular & $25(4 \%)$ \\
\hline Missing data & $4(0.6 \%)$ \\
\hline Smoking, pack-years ${ }^{2}(n=683)$ & $14.0(0-145.5)$ \\
\hline \multicolumn{2}{|l|}{ DNA methylation, $\% 5 \mathrm{mC}^{1}$} \\
\hline Alu $(n=689)$ & $26.4(1.1)$ \\
\hline LINE-1 $(\mathrm{n}=681)$ & $76.8(1.8)$ \\
\hline
\end{tabular}

serve as a surrogate for diffuse genomic DNA methylation changes. The degree of methylation was expressed as the percentage of methylated cytosines of the sum of methylated and unmethylated cytosines. This method quantitatively assessed the proportion of methylated sites in LINE-1 and Alu repetitive elements dispersed throughout the genome. Non-CpG cytosine residues were used as built-in controls to verify bisulfite conversion. For both Alu and LINE-1, we measured the percentage of methylated cytosines at each of three $\mathrm{CpG}$ dinucleotide positions that are repeated over the human genome with the sequence of interest. Each marker was tested in triplicate, and their average was used in the statistical analysis.

\section{Skin Testing and IgE}

Skin prick testing was conducted an average of 8 years prior to blood sample collection. Skin testing was performed as previously described [24] by the prick method of Pepys [25]. Subjects were tested in a double-blind fashion with 4 common aeroallergen preparations preserved in glycerin (ragweed, 1:20; mixed trees, 1:20; mixed grasses, 1:20; house dust, 1:10) along with a glycerin control. Wheal reactions were measured at $20 \mathrm{~min}$ as the sum of the largest wheal diameter plus the perpendicular diameter divided by 2 . A positive skin test was defined as subjects having a wheal diameter of $\geq 5 \mathrm{~mm}$ in response to any of the above allergens, after subtraction of the glycerin control. Of the 704 men with DNA methylation data, 591 (84\%) had prior assessment for allergen sensitization. Serum total IgE was determined by a paper radioimmunosorbent test (Pharmacia Diagnostics, Piscataway, N.J., USA) an average of 8 years prior to blood sample collection for DNA methylation (range 6-17.5 years). The mean of 2 determinations on each serum specimen was used for analysis.

\section{Methacholine Challenge Protocol}

Methacholine challenge testing was performed on the same day as skin prick testing. Sixty percent of men with DNA methylation assessment (423/704) also had methacholine challenge testing [24]. Protocols for methacholine challenge testing were performed as previously reported [26]. A positive methacholine challenge test (airway hyperresponsiveness) was defined as a $\geq 20 \%$ decline in forced expiratory volume in $1 \mathrm{~s}\left(\mathrm{FEV}_{1}\right)$ from the postsaline value at or before one inhalation of $25 \mathrm{mg} / \mathrm{ml}$ methacholine. Men with a $\geq 20 \%$ decline in $\mathrm{FEV}_{1}$ from the postsaline value at or before four inhalations of $5 \mathrm{mg} / \mathrm{ml}$ methacholine (equivalent to a cumulative dose of $8.58 \mu \mathrm{mol}$ of methacholine) were classified as responders.

Statistical Analysis

We used multiple linear regression models to determine the association between prior allergen sensitization and markers of DNA methylation of Alu and LINE-1. Distributions of Alu and LINE-1 were approximately normal, so these outcome variables were untransformed in the analyses. For models of allergen sensitization and DNA methylation, we used atopy (sensitization to any allergen) and specific allergen sensitization as predictors. Both univariate and multiple regression models for specific allergen sensitization were constructed. We also considered asthma and methacholine responsiveness as predictors of DNA methylation. Models were adjusted for body mass index, age at blood sampling for DNA methylation analysis, pack-years of smoking, current smoking, air pollutants (7-day moving averages of particles less than $2.5 \mu \mathrm{m}$ in diameter and black carbon), percentage of eosinophils in the peripheral blood cell count and total white blood cell count. Air pollutant exposures at the time of blood sample collection were assessed using a stationary monitoring site $1 \mathrm{~km}$ from the examination site. We also examined dietary folate (estimated from a food frequency questionnaire) as a predictor of DNA methylation and as a potential confounder in multiple regression models.

\section{Results}

The characteristics of the study population are shown in table 1 . The study subjects were older male individuals between the ages of 55.3 and 100.9 years (mean age 72.7 , SD 6.7). Mean blood DNA methylation levels, expressed as the percentage of methylated cytosines, were 26.4 (SD 1.1, range 22.8-32.4) for Alu and 76.8 (SD 1.8, range 70.184.6) for LINE-1 methylation.

\section{Prior Allergen Sensitization and DNA Methylation of Repetitive Elements}

Twenty percent of the men tested for allergen sensitization were sensitized to at least one allergen (table 2). In men sensitized to at least one allergen, mean DNA methylation levels were 26.6 (SD 1.2, range 23.6-30.7) for Alu and 76.9 (SD 1.8, range 71.1-81.0) for LINE-1; for unsensitized men, mean levels were 26.2 (SD 0.96, range 22.830.1) for Alu and 76.8 (SD 1.8, range 70.1-84.6) for LINE1 methylation. In multiple regression models, prior sensitization to at least one allergen was associated with a 0.32 increase in the methylation of Alu $(p=0.003)$ but showed no association $(\mathrm{p}=0.63)$ with LINE-1 methylation 


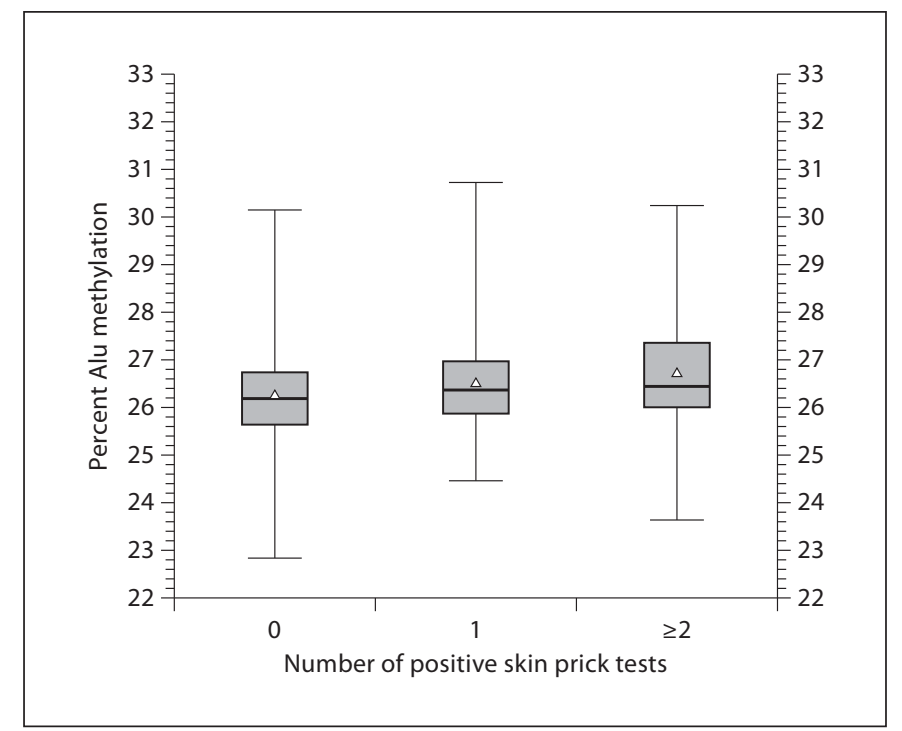

Fig. 1. Percent Alu methylation with increasing number of positive skin prick tests (SPT). $\mathrm{p}=0.005$ for trend in the adjusted model, for SPT $=0(n=470)$, SPT $=1(n=83)$ and SPT $\geq 2(n=$ 38). Whiskers represent the range, boxes represent quartiles and triangles represent the mean.

Table 2. Respiratory and allergic disease outcomes in the Normative Aging Study cohort

\begin{tabular}{lc}
\hline $\mathrm{IgE}, \mathrm{IU} / \mathrm{ml}^{1}(\mathrm{n}=469)$ & $31.6 \pm 4.2$ \\
Atopy, $\mathrm{n}$ & \\
$\quad$ No & $170(80 \%)$ \\
$\quad$ Yes & $121(20 \%)$ \\
Methacholine response, $\mathrm{n}$ & $323(76 \%)$ \\
$\quad$ No & $100(24 \%)$ \\
$\quad$ Yes & \\
Asthma, $\mathrm{n}$ & $634(95 \%)$ \\
$\quad$ No & $35(5 \%)$ \\
$\quad$ Yes & \\
\hline
\end{tabular}

Atopy was defined as any positive skin prick test with a wheal diameter of $\geq 5 \mathrm{~mm}$. Methacholine response was defined as a $20 \%$ decline in $\mathrm{FEV}_{1}$.

${ }^{1}$ Geometric mean $\pm \mathrm{SD}$.

(table 3). Adjustment for potential confounders did not alter this effect. Dietary folate consumption was not associated with methylation of Alu or LINE-1 and did not confound the relationship between allergen sensitization and DNA methylation (data not shown). Adjustment for air pollutants (levels of particles less than $2.5 \mu \mathrm{m}$ in diameter and black carbon) did not change the association between allergen sensitization and DNA methylation. Alu methylation increased with each additional positive skin prick test ( $\beta=0.21, p<0.05$ in adjusted models; fig. 1$)$. Total IgE levels were not associated with methylation of either Alu or LINE-1 elements ( $p>0.25)$. The percentage of blood eosinophils was elevated in sensitized versus nonsensitized individuals ( 4.0 vs. $3.4 \%$, respectively; $p$ value for $\mathrm{t}$ test $=0.03$ ) but was not associated with DNA methylation. Of the men who tested positive for allergen sensitization, $6 \%$ were sensitized to tree allergens, $12 \%$ to grass, $9 \%$ to ragweed and $2.5 \%$ to house dust extract. In univariate models, specific allergies to tree $(p=0.007)$ and grass $(\mathrm{p}=0.07)$ were associated with increased methylation of Alu but not LINE-1 (table 4). However, in multiple regression models including a panel of specific allergies, only sensitization to tree allergens was significantly associated with increased methylation of Alu. Specific allergen sensitization was not associated with LINE-1 methylation in multiple regression models $(\mathrm{p}=0.63)$. The percentage of methacholine responders was also similar in sensitized versus nonsensitized subjects ( 22 vs. $25 \%$; $\mathrm{p}=0.5$ ).

\section{Methacholine Responsiveness and DNA Methylation of Repetitive Elements}

One quarter of the men tested for bronchial hyperresponsiveness showed a $\geq 20 \%$ drop in $\mathrm{FEV}_{1}$ (table 2). Methacholine responsiveness was not associated with methylation of Alu or LINE-1 (table 5). Similarly, methacholine responsiveness expressed as a continuous variable (log10 slope of response) showed no significant relationship with DNA methylation (data not shown).

\section{Asthma and DNA Methylation of Repetitive Elements}

Five percent of men with DNA methylation data $(\mathrm{n}=$ 35) reported a doctor's diagnosis of asthma. Thirty-nine percent of self-reported asthmatics (12 out of 31 with skin prick testing) tested positive for allergen sensitization. Asthma was not associated with Alu and LINE-1 methylation levels in adjusted models (table 5).

\section{Discussion}

Our study shows that prior allergen sensitization is associated with increased DNA methylation of the repetitive element Alu in a cohort of elderly men. No associations with allergic disease were observed for LINE-1. Hypermethylation of DNA from sensitized individuals suggests a potential underlying epigenetic mechanism for altered immune response in allergic disease. Although a 
Table 3. Allergy as a predictor of global DNA methylation

\begin{tabular}{|c|c|c|c|c|}
\hline & \multicolumn{2}{|l|}{ Alu } & \multicolumn{2}{|l|}{ LINE-1 } \\
\hline & $\bar{\beta}$ & $\mathrm{p}$ value & $\bar{\beta}$ & $\mathrm{p}$ value \\
\hline Model 1 & $(\mathrm{n}=553)$ & & $(\mathrm{n}=552)$ & \\
\hline Prior positive allergic sensitization (SPT+) & 0.32 & 0.003 & 0.09 & 0.63 \\
\hline Eosinophils (\% of total WBC count) & 0.007 & 0.70 & 0.05 & 0.12 \\
\hline Model 2 & $(\mathrm{n}=437)$ & & $(\mathrm{n}=435)$ & \\
\hline $\log 10 \operatorname{IgE}(\mathrm{IU} / \mathrm{ml})$ & 0.09 & 0.26 & 0.09 & 0.54 \\
\hline Eosinophils (\% of total WBC count) & 0.006 & 0.80 & 0.01 & 0.72 \\
\hline
\end{tabular}

$\mathrm{SPT}+=$ Positive skin prick test; $\mathrm{WBC}=$ white blood cell. Both models were adjusted for body mass index, age, pack-years of smoking, current smoking, total white blood cell count and air pollutants (7-day moving average of particles less than $2.5 \mathrm{~m}$ in diameter and black carbon levels).

Table 4. Specific allergic sensitization and global DNA methylation

\begin{tabular}{|c|c|c|c|c|c|c|c|c|c|}
\hline & \multirow[t]{3}{*}{ SPT+ } & \multicolumn{4}{|c|}{ Univariate models } & \multicolumn{4}{|c|}{ Multiple regression models } \\
\hline & & \multicolumn{2}{|l|}{$\overline{\mathrm{Alu}}$} & \multicolumn{2}{|c|}{ LINE-1 } & \multicolumn{2}{|l|}{ Alu } & \multicolumn{2}{|c|}{ LINE-1 } \\
\hline & & $\beta$ & $\mathrm{p}$ value & $\beta$ & $\mathrm{p}$ value & $\beta$ & $\mathrm{p}$ value & $\beta$ & $\mathrm{p}$ value \\
\hline Tree & $37(6 \%)$ & 0.48 & 0.007 & 0.35 & 0.26 & 0.38 & 0.05 & 0.43 & 0.21 \\
\hline Grass & $68(12 \%)$ & 0.24 & 0.07 & 0.08 & 0.72 & 0.19 & 0.18 & 0.03 & 0.89 \\
\hline House dust & $15(2.5 \%)$ & 0.44 & 0.11 & 0.29 & 0.54 & 0.49 & 0.09 & -0.07 & 0.88 \\
\hline Ragweed & $50(8.5 \%)$ & 0.22 & 0.15 & -0.03 & 0.92 & -0.12 & 0.49 & -0.09 & 0.76 \\
\hline
\end{tabular}

Multiple regression models were adjusted for age, body mass index, pack-years of smoking, current smoking, percent eosinophils, total white blood cell count and air pollutants (7-day moving average of particles less than $2.5 \mu \mathrm{m}$ in diameter and black carbon levels). SPT $+=$ Positive skin prick test.

Table 5. Respiratory outcomes and methylation of repetitive elements

\begin{tabular}{llllll}
\hline & Alu & & & LINE-1 & \\
\cline { 5 - 6 } & $\beta$ & p value & & $\beta$ & p value \\
\hline Model 1 & $(\mathrm{n}=609)$ & & & $(\mathrm{n}=605)$ & \\
Self-reported asthma diagnosis & -0.20 & 0.36 & & 0.03 & 0.81 \\
\hline Model 2 & $(\mathrm{n}=395)$ & & & $(\mathrm{n}=391)$ & \\
Methacholine responsiveness & 0.07 & 0.57 & & 0.06 & 0.37 \\
\hline
\end{tabular}

Both models were adjusted for body mass index, age, pack-years of smoking, current smoking, percent eosinophils, total white blood cell count and air pollutants (7-day moving average of particles less than $2.5 \mu \mathrm{m}$ in diameter and black carbon levels). 
considerable amount of epigenetic programming occurs during fetal development [27], the association between increased Alu methylation and allergen sensitization in this older population suggests that epigenetic changes in later life may also be relevant for allergy. Epigenetic modifications in adulthood may occur as a result of the aging process or due to environmental exposures. In this cohort, aging [28, 29], lead exposure [30], and air pollution [31] have all been associated with a decrease in methylation of repetitive elements in DNA. In contrast, dietary consumption of methyl donors may increase DNA methylation levels, potentially leading to an increased risk of allergic disease. Human and animal studies of prenatal exposures have shown a link between consumption of high levels of folate during pregnancy and increased risk of allergies and asthma in offspring [6, 14]. Folate consumption was not associated with DNA methylation in this cohort. However, data on folate supplementation and DNA methylation in humans are mixed [32-34], and the relationship between methyl donor consumption, allergies and asthma in adults requires further study.

While prior allergen sensitization was associated with increased Alu methylation in this cohort, we did not find similar effects for total IgE levels or methacholine responsiveness. Total IgE as a marker of allergen sensitization is much less specific than skin prick testing, which could explain why we did not observe an effect for this predictor. Methacholine response showed a minimal overlap with sensitization, with only $20 \%$ of responders demonstrating sensitization to at least one allergen. This limited overlap may explain why a concomitant association was not detected for methacholine responsiveness and Alu methylation. An alternative explanation may relate to statistical power. Our sample size was larger for subjects with skin prick test data $(\mathrm{n}=591)$, as compared to the number of subjects with IgE measurement $(\mathrm{n}=469)$ or methacholine responsiveness $(n=423)$.

Since epigenetic patterns may be influenced by cell populations, we adjusted for the percentage of eosinophils, which was elevated in subjects with allergen sensitization. The relationship between prior allergen sensitization and DNA methylation remained unchanged after adjustment for the percentage of eosinophils. While sensitization to any allergen was significantly associated with increased methylation of Alu, multiple regression models examining individual specific allergies showed tree sensitization as the strongest predictor.

Methylation of repetitive DNA sequences like Alu and LINE-1 may serve as a broad indicator of global DNA methylation (with potential implications for groups of specific genes involved in allergy, like those in T cell differentiation and adaptive immunity), or the repetitive elements themselves may alter immune function in a way that influences allergy. While the majority of Alu copies are hypermethylated and therefore inactive, hypomethylation (as a result of vitamin B deficiency, treatment with medications such as 5 -azacytidine, procainamide and hydralazine, or toxin exposure) results in transcription of Alu elements [18]. Transcripts of this transposon-derived DNA are perceived as 'foreign' to the immune system and may have immune-stimulatory capabilities. Additionally, the unmethylated CpG-rich Alu DNA fragments could potentially mimic the effects of bacterial CpG-rich motifs, which are known to prime the Th1 response, suppress IgE production and initiate the release of the cytokines interleukin-12 and IFN- $\gamma$ [35].

While this study showed a clear association between allergen sensitization and increased DNA methylation, there were some study limitations. The allergen sensitization data in the cohort were collected several years prior to DNA methylation data; therefore, we were not able to assess the association between current allergen sensitization and DNA methylation. While sensitization to tree allergens seemed to drive the relationship between current allergen sensitization and methylation, the number of subjects within this subgroup was relatively small. Also, our analysis was limited to older, predominantly white men. Lastly, although methylation of repetitive elements may represent epigenetic modifications in a large portion of the genome, the significance of these epigenetic markers can be difficult to interpret.

In summary, this study suggests that increased methylation of repetitive elements may be associated with allergen sensitization, but not asthma, in this cohort. Future work is needed to identify potential underlying mechanisms for these relationships.

\section{Acknowledgements}

We would like to thank the Normative Aging Study subjects for their participation. The Normative Aging Study is supported by the Cooperative Studies Program/Epidemiology Research and Information Center of the US Department of Veterans Affairs and is a component of the Massachusetts Veterans Epidemiology Research and Information Center. Dr. Sparrow is the recipient of a Research Career Scientist award from the Veterans Affairs Clinical Science Research and Development Service.

This study was funded by National Institutes of Health grants AG027214, ES015172, 014663, HL007427, HL089438, ES01517201 and ES00002 and the Doris Duke Clinical Scientist Development Award. 


\section{References}

$\checkmark 1$ Feinberg AP: Phenotypic plasticity and the epigenetics of human disease. Nature 2007; 447:433-440.

-2 Edwards TM, Myers JP: Environmental exposures and gene regulation in disease etiology. Environ Health Perspect 2007;115: 1264-1270.

- 3 Janson PC, Winerdal ME, Winqvist O: At the crossroads of $\mathrm{T}$ helper lineage commitment - epigenetics points the way. Biochim Biophys Acta 2009;1790:906-919.

-4 White GP, Hollams EM, Yerkovich ST, Bosco A, Holt BJ, Bassami MR, Kusel M, Sly PD, Holt PG: CpG methylation patterns in the IFN gamma promoter in naive $T$ cells: variations during Th1 and Th2 differentiation and between atopics and non-atopics. Pediatr Allergy Immunol 2006;17:557-564.

5 White GP, Watt PM, Holt BJ, Holt PG: Differential patterns of methylation of the IFNgamma promoter at $\mathrm{CpG}$ and non-CpG sites underlie differences in IFN-gamma gene expression between human neonatal and adult CD45RO- T cells. J Immunol 2002; 168: 2820-2827.

6 Whitrow MJ, Moore VM, Rumbold AR, Davies MJ: Effect of supplemental folic acid in pregnancy on childhood asthma: a prospective birth cohort study. Am J Epidemiol 2009; 170:1486-1493.

7 Winders BR, Schwartz RH, Bruniquel D: A distinct region of the murine IFN-gamma promoter is hypomethylated from early $\mathrm{T}$ cell development through mature naive and Th1 cell differentiation, but is hypermethylated in Th2 cells. J Immunol 2004;173:73777384.

$\checkmark 8$ Yano S, Ghosh P, Kusaba H, Buchholz M, Longo DL: Effect of promoter methylation on the regulation of IFN-gamma gene during in vitro differentiation of human peripheral blood $\mathrm{T}$ cells into a Th2 population. J Immunol 2003;171:2510-2516.

-9 Lee GR, Kim ST, Spilianakis CG, Fields PE, Flavell RA: T helper cell differentiation: regulation by cis elements and epigenetics. Immunity 2006;24:369-379.

10 Polansky JK, Kretschmer K, Freyer J, Floess S, Garbe A, Baron U, Olek S, Hamann A, von Boehmer H, Huehn J: DNA methylation controls Foxp3 gene expression. Eur J Immunol 2008;38:1654-1663.

11 Sanders VM: Epigenetic regulation of Th1 and Th2 cell development. Brain Behav Immun 2006;20:317-324.

-12 Bousquet J, Jacot W, Yssel H, Vignola AM, Humbert M: Epigenetic inheritance of fetal genes in allergic asthma. Allergy 2004;59: 138-147.
13 Miller RL, Ho SM: Environmental epigenetics and asthma: current concepts and call for studies. Am J Respir Crit Care Med 2008;177:567-573.

14 Hollingsworth JW, Maruoka S, Boon K, Garantziotis S, Li Z, Tomfohr J, Bailey N, Potts EN, Whitehead G, Brass DM, Schwartz DA: In utero supplementation with methyl donors enhances allergic airway disease in mice. J Clin Invest 2008;118:3462-3469.

$\checkmark 15$ Magdelijns FJ, Mommers M, Penders J, Smits L, Thijs C: Folic acid use in pregnancy and the development of atopy, asthma, and lung function in childhood. Pediatrics 2011; 128:e135-e144.

16 Faulkner GJ, Kimura Y, Daub CO, Wani S, Plessy C, Irvine KM, Schroder K, Cloonan N, Steptoe AL, Lassmann T, Waki K, Hornig N, Arakawa T, Takahashi H, Kawai J, Forrest AR, Suzuki H, Hayashizaki Y, Hume DA, Orlando V, Grimmond SM, Carninci P: The regulated retrotransposon transcriptome of mammalian cells. Nat Genet 2009;41:563571.

17 Cordaux R, Batzer MA: The impact of retrotransposons on human gene evolution. Nat Rev Genet 2009;10:691-703.

18 Goldberg B, Urnovitz HB, Stricker RB: Beyond danger: unmethylated $\mathrm{CpG}$ dinucleotides and the immunopathogenesis of disease. Immunol Lett 2000;73:13-18.

19 Crow MK: Long interspersed nuclear elements (LINE-1): potential triggers of systemic autoimmune disease. Autoimmunity 2010; 43:7-16.

20 Bell B, Rose C, Damon A: The normative aging study: an interdisciplinary and longitudinal study of health and aging. Aging Hum Dev 1972;3:4-17.

21 Ferris BG: Epidemiology Standardization Project (American Thoracic Society). Am Rev Respir Dis 1978;118:1-120.

22 Bollati V, Baccarelli A, Hou L, Bonzini M, Fustinoni S, Cavallo D, Byun HM, Jiang J, Marinelli B, Pesatori AC, Bertazzi PA, Yang AS: Changes in DNA methylation patterns in subjects exposed to low-dose benzene. Cancer Res 2007;67:876-880.

23 Yang AS, Estecio MR, Doshi K, Kondo Y, Tajara EH, Issa JP: A simple method for estimating global DNA methylation using bisulfite PCR of repetitive DNA elements. Nucleic Acids Res 2004;32:e38.

24 Sparrow D, O'Connor G, Colton T, Barry CL, Weiss ST: The relationship of nonspecific bronchial responsiveness to the occurrence of respiratory symptoms and decreased levels of pulmonary function. The Normative Aging Study. Am Rev Respir Dis 1987;135: 1255-1260.
25 Pepys J: Skin tests. Br J Hosp Med 1984;32: $120,122,124$

26 Chatham M, Bleecker ER, Norman P, Smith PL, Mason P: A screening test for airways reactivity. An abbreviated methacholine inhalation challenge. Chest 1982;82:15-18.

27 Szyf M: The early life environment and the epigenome. Biochim Biophys Acta 2009; 1790:878-885.

28 Bollati V, Schwartz J, Wright R, Litonjua A, Tarantini L, Suh H, Sparrow D, Vokonas P, Baccarelli A: Decline in genomic DNA methylation through aging in a cohort of elderly subjects. Mech Ageing Dev 2009;130:234239.

29 Zhu ZZ, Hou L, Bollati V, Tarantini L, Marinelli B, Cantone L, Yang AS, Vokonas P, Lissowska J, Fustinoni S, Pesatori AC, Bonzini M, Apostoli P, Costa G, Bertazzi PA, Chow WH, Schwartz J, Baccarelli A: Predictors of global methylation levels in blood DNA of healthy subjects: a combined analysis. Int J Epidemiol 2012;41:126-139.

- 30 Wright RO, Schwartz J, Wright RJ, Bollati V, Tarantini L, Park SK, Hu H, Sparrow D, Vokonas P, Baccarelli A: Biomarkers of lead exposure and DNA methylation within retrotransposons. Environ Health Perspect 2010;118:790-795.

- 31 Baccarelli A, Wright RO, Bollati V, Tarantini L, Litonjua AA, Suh HH, Zanobetti A, Sparrow D, Vokonas PS, Schwartz J: Rapid DNA methylation changes after exposure to traffic particles. Am J Respir Crit Care Med 2009; 179:572-578.

32 Pufulete M, Al-Ghnaniem R, Khushal A, Appleby P, Harris N, Gout S, Emery PW, Sanders TA: Effect of folic acid supplementation on genomic DNA methylation in patients with colorectal adenoma. Gut 2005;54: 648-653.

- 33 Schiepers OJ, van Boxtel MP, de Groot RH, Jolles J, Kok FJ, Verhoef P, Durga J: DNA methylation and cognitive functioning in healthy older adults. Br J Nutr 2012;107:744748.

-34 Basten GP, Duthie SJ, Pirie L, Vaughan N, Hill MH, Powers HJ: Sensitivity of markers of DNA stability and DNA repair activity to folate supplementation in healthy volunteers. Br J Cancer 2006;94:1942-1947.

35 Chaung HC: CpG oligodeoxynucleotides as DNA adjuvants in vertebrates and their applications in immunotherapy. Int Immunopharmacol 2006;6:1586-1596. 